\title{
Pembelajaran Akidah Akhlak Berwawasan Peduli Lingkungan di MAN 1 Lamongan
}

\author{
Saifuddin \\ Universitas Islam Majapahit Mojokerto \\ fathirsurendra@gmail.com
}

\section{Article History:}

Received : 10-01-2019

Revised : 21- 02-2019

Accepted : 05-03-2019

\begin{abstract}
In this study the researchers raised the problem of increasing the character of caring for the environment by implementing Akidah Akhlak learning for students of MAN 1 Lamongan, in this study, several things will be examined, namely 1) the objectives of learning Akidah Akhlak in improving the character of caring for the environment? 2) the process of learning Akidah Akhlak in enhancing the character of caring for the environment? 3) Resources for improving the character of environmental care? Researchers use qualitative methods and a case study approach. The results of this study indicate that learning Akidah Akhlak has a role and purpose of improving the character of caring for the environment. Second, the two subjects of Akidah Akhlak in enhancing the character of caring for the environment are articulated using methods, media and strategies. Third, the resources used in the Akidah Akhlak learning process in improving the character of caring for the environment, among others, are through human resources, teaching materials, media and activities that occur in the learning process. Thus this researcher found that learning Akidah Akhlak could increase understanding and concern for the environment.
\end{abstract}

Keywords: intruction, Aqeedah, enviromental care

\section{Pendahuluan}

Akidah menurut bahasa,berasal dari kata 'aqada ya'qidu aqidah yang artinya adalah ikatan atau perjanjian. ${ }^{1}$ Dari hal itu dapat kita artikan bahwa Akidah adalah dasar pokok pokok atau kepercayaan atau keyakinan hati seorang muslim yang bersumber dari ajaran islam yang wajib di punyai oleh setiap muslim sebagai sumber keyakinan dan yang mengikat. Sedangkan Akhlak menurut Ibrahim Anis mengatakan bahwa akhlakh adalah Sifat yang tertanam dalam jiwa,yang denganya lahir macam macam perbuatan baik atau buruk, tampa membutuhkan pemikiran ataupun pertimbangan. ${ }^{2}$

\footnotetext{
${ }^{1}$ Darwis Abu Ubaidah, Panduan Akidah Ahlu Sunnah Wal Jamaah, Jakarta : Pustaka Al-Kautsar, 2008, cet 1,9 .

${ }^{2}$ Abuddin Nata, M, Akhlak Tasawuf, (Jakarta : PT Raja Grafindo Persada,1996), 4.
} 
Pembelajaran Aqidah Akhlak memang dirasa perlu, mengingat pendidikan Akhlak sangat berpengaruh dalam kehidupan manusia baik untuk dirinya maupun untuk lingkungan sekitarnya, sebab akhir ini banyak manusia yang melakukan kegiatan kegiatan yang menyebabkan kerusakan kepada lingkunganya dan menyebabkann berbagai bencana yang bermunculan. Oleh karena itu pembelajaran Akidah Akhlak diharapkan mampu menjadikan siswa siswi mampu menjaga lingkungan, menjaga tingkah laku yang akan dilakukan sebab pembelajaran pada Akidah Akhlak berisi tentang etika, norma, penanaman Akhlak yang baik. Perwujudan

Pendidikan Agama Islam tidak hanya terpacu pada pendidikan saja namun juga dengan lingkungannya, hal tersebut termuat dalam ruang lingkup Pendidikan Agama Islam meliputi keserasia, keselarasan dan keseimbangan antara lain :

1. Hubungan manusia dengan Allah SWT

2. Hubungan manusia dengan sesama manusia

3. Hubungan manusia dengan dirinya sendiri

4. Hubungan manusia dengan makhluk lain dan lingkunganya. ${ }^{3}$

Dalam ruang lingkup tersebut pada pembelajaran Akidah Akhlak sangat di butuhkan dalam menjaga ke seimbangan dan keselarasan pendidikan agama islam, seperti adanya usaha pelestarian lingkungan seperti yaitu terselenggaranya lembaga pendidikan yang berwawasan lingkungan.

MAN 1 Lamongan adalah salah satu sekolahan yang mendapat penghargaan dialam program ADIWIYATA di tahun 2018-2020. Man 1 Lamongan juga menjadi sekolah rujukan adiwiyata utama di Adipura yang pada saat itu pernah didatangi oleh bapak Bupati Lamongan. Hubungan antara pembelajaran MAN 1 Lamongan dengan program adiwiyata yaitu sesuai dengan visi dari sekolahan salah satunya yaitu harus cinta lingkungan dan harus merawat lingkungan.

Pak Asman selaku guru Akidah Akhlak memiliki pandangan akan peran pembelajaran Akidah Akhlak dalam meningkatkan karakter peduli lingkungan "dengan pembelajaran Akidah Akhlak siswa mampu mengetahui adab, seperti adab dalam bergaul, adab dengan lawan jenis serta pada lingkungan dan melestarikanya. Akidah Akhlak juga dapat membentuk karakter yang baik pada siswa,jika Akidah Akhlaknya bagus maka Akhlak pada anak nya juga bagus,namun jika Akidah Akhlaknya buruk maka begitu juga dengan karakternya"

Dengan adanya program ini peneliti ingin mengetahui bagaimana konstruksi Mata Pelajaran Akidah Ahlak yang berkaitan dengan tujuan pembelajaran Akidah Akhlak, proses pembelajaran Akidah Akhlak, sumber daya Lingkungan, Konstruksi Mata Pelajaran Akidah Akhlak yang di terapkan dalam sekolah Menengah Atas program Adiwiyata atau sekolah peduli lingkungan yang ada di kota Lamongan. Dengan ini penyusun tertarik untuk melakukan penelitian tentang bagaimana "Implementasi Pembeajaran Akidah Akhlak dalam Meningkatkan Karakter Peduli Lingkungkungan di Sekolah Adiwiyata MAN 1 Lamongan".

\footnotetext{
${ }^{3}$ Ramayulis,Metodologi Pendidikan Agama Islam. (Jakarta : Kalam Mulia,2014), 22.
} 
Penelitian ini menggunakan jenis penelitian kualitatif dengan pendekatan studi kasus. Subyek penelitiannya adalah Guru Akidah Akhlak, siswa MAN 1 Lamongan. Sumber dan jenis penelitiannya ada dua yaitu data primer dan data sekunder. Data primer data hasil wawancara dan data sekunder data dari dokumentasi sekolah. Teknik pengumpulan data dalam penelitian ini menggunakan tiga cara yaitu observasi partisipatif, wawancara semi terstruktur dan dokumentasi. Teknik analisa data dalam penelitian ini menggunakan tiga cara yaitu Reduksi data, Penyajian data dan verifikasi. Pengecekkan keabsahan datanya menggunakan triangulasi data, meliputi triangulasi sumber, triangulasi teknik dan triangulasi waktu.

\section{Pembelajaran: Tujuan dan Metode Aplikasinya}

Kata pembelajaran berasal dari kata dasar belajar, dalam arti sempit, pembelajaran merupakan suatu proses belajar agar seseorang dapat melakukan kegiatan belajar. Sedangkan belajar adalah suatu proses perubahan tingkah laku karena interaksi individu dengan lingkungan dan pengalaman. ${ }^{4}$ Selain itu terdapat pengertian lain mengenai pembelajaran yaitu pembelajaran merupakan suatu proses dua arah, mengajar dilakukan oleh guru sebagai pendidik, sedangkan belajar dilakukan oleh peserta didik atau murid. Konsep pembelajaran menurut Corey adalah suatu proses dimana lingkungan seseorang secara sengaja di kelolah untuk memungkinkan ia turut serta dalam tingkah laku tersebut dalam kondisi kondisi khusus dari pendidikan. ${ }^{5}$

Sedangkan menurut Gagne dan Briggs, pembelajaran merupakan suatu sistem yang bertujuan untuk membantu proses belajar anak didik, yang dirancang, sedemikian rupa mendukung terjadinya proses belajar anak didik yang bersifat internal. ${ }^{6}$

Dari beberapa pendapat tersebut, maka dapat disimpulkan bahwa, pembelajaran merupakan proses yang dilakukan oleh pendidik untuk membelajarkan peserta didik pada lingkungan belajar tertentu dan akhirnya terjadi perubahan tingkah laku. Oleh karena pembelajaran merupakan proses, tentu dalam sebuah proses terdapat komponen-komponen yang saling terkait. Komponen-komponen pokok dalam pembelajaran mencakup tujuan pembelajaran, pendidik, peserta didik, kurikulum, strategi pembelajaran, media pembelajaran, dan evaluasi pembelajaran. ${ }^{7}$ hubungan antara komponen-komponen pembelajaran tersebut salah satunya akan membentuk suatu kegiatan yang bernama proses pembelajaran.

Proses pembelajaran merupakan keseluruhan kegiatan yang dirancang untuk membelajarkan peserta didik. Pada satuan pendidikan, proses pembelajaran diselenggarakan secara interaktif, inspiratif, menyenangkan, menantang, memotivasi peserta didik untuk berpartisipasi aktif sesuai dengan bakat, minat dan perkembangan

\footnotetext{
${ }^{4}$ Zainal Arifin, Evaluasi Pembelajara, (Bandung: PT Remaja Rosdakarya, 2012), 10

${ }^{5}$ Dr. H. Syaiful Sagala, Konsep dan Makna Pembelajaran, (Bandung : ALFABETA, 2008), 61

${ }^{6}$ Syaiful Bahri Djamarah, Guru dan Anak Didik, (Jakarta: Rineka Cipta, 2010),325

${ }^{7}$ Glendoni, Komponen-Komponen Pembelajaran, diakses 30 Oktober 2013
} 
fisik serta psikologis peserta didik. ${ }^{8}$ Di Indonesia Proses pembelajaran pada satuan pendidikan dasar dan menengah diatur dalam standar proses.

Berdasarkan Peraturan Menteri Pendidikan Nasional (Permendiknas) Nomor 41 tahun 2007 tentang standar proses untuk satuan pendidikan dasar dan menengah, bahwa standar proses berisi kriteria minimal proses pembelajaran pada satuan pendidikan dasar dan menengah diseluruh wilayah hukum Negara Kesatuan Republik Indonesia. Standar proses meliputi perencanaan proses pembelajaran, pelaksanaan proses pembelajaran, penilaian hasil pembelajaran, dan pengawasan hasil pembelajaran untuk terlaksananya proses pembelajaran yang efektif dan efisien. ${ }^{9}$

\section{Perencanan proses Pembelajaran}

Perencanaan berasal dari kata rencana yang artinya pengambilan keputusan tentang apa yang harus dilakukan untuk mencapai tujuan. ${ }^{10}$ Maka dari itu, perencanaan harus dimulai dari penetapan tujuan yang akan dicapai, kemudian menetapkan langkahlangkah yang harus dilakukan untuk mencapai tujuan tersebut. Hal ini sejalan dengan Hamzah B. Uno yang menyatakan bahwa perencanaan merupakan suatu cara yang memuaskan untuk membuat kegiatan dapat berjalan dengan baik, disertai dengan berbagai langkah yang antisipatif guna memperkecil kesenjangan yang terjadi sehingga kegiatan tersebut mencapai tujuan yang telah ditetapkan.

Dalam konteks pembelajaran, perencanaan dapat diartikan sebagai proses penyusunan materi pelajaran, penggunaan media pembelajaran, penggunaan pendekatan dan metode pembelajaran serta penilaian dalam suatu alokasi waktu yang akan dilaksanakan pada masa tertentu untuk mencapai tujuan yang telah ditentukan. ${ }^{11}$

2. Metode Pembelajaran.

Metode dalam bahasa arab, dikenal dengan istilah thariqah yang berarti langkah langkah strategis yang dipersiapkan untuk melakukan suatu pekerjaan. ${ }^{12}$ Metode mengajar dapat diartikan senagai cara yang dipergunakan oleh pendidik dalam mengadakan hubungan dengan peserta didik pada saat berlangsungnya proses pebelajaran. Dengan demikian metode mengajar merupakan alat untuk menciptakan proses pembelajaran.

Langlulung mendefinisikann bahwa metide adalah cara atau jalan yang harus dilalui untuk mencapai tujuan pendidikan. Dalam proses pembelajaran metode sangat berperang penting karena metode merupakan bagian penting dalam proses pembelajaran.

\footnotetext{
${ }^{8}$ Dedi Mulyasana, Pendidikan Bermutu dan Berdaya Saing, (Bandung: PT. Remaja Rosdakarya, 2012), 155

${ }^{9}$ Peraturan Menteri Pendidikan Nasional No.41 tahun 2007 pasal 1 tentang standar proses penmbelajaran untuk satuan menengah

${ }^{10}$ Wina Sanjaya, Perencanaan dan Desain Sistem Pembelajaran, (Jakarta: Kencana, 2008), 23

${ }^{11}$ Abdul Majid, Perencanaan Pembelajaran, (Bandung: PT Remaja Rosdakarya, 2008), 1

${ }^{12}$ Shalih Abd. Aziz,At-Tarbiyah Al Haditsah Maddatuhah,Mabadi'uba,tatliiqatuhah al-amaaliyah (At-ta secara lisan oleh pendidikrbiyah wa Thuruq Al-tadris), (Kairoh Dar al-Ma'arif,1119 H), 196
} 


\section{Tujuan Pembelajaran Akidah Akhlak berwawasan Peduli Lingkungan}

Berdasarkan teori tentang Tujuan Pendidikan Nasional yang bersumber dari system nilai pancasila dirumuskan dalam UUD No.20 Tahun 2003, pasal 3, yang merumuskan bahwa tujuan pedidikan nasional terdiri dari tujuan institusional yaitu mengembangkan kemampuan dan bentuk watak serta peradapan bangsa yang bermartabat dalam rangka mencerdaskan kehidupan bangsa dan tujuan instruksional yaitu dengan mengembangkan kemampuan potensi peserta didik agar menjadi manusia yang beriman dan bertaqwa kepada Tuhan Yang Maha Esa. ${ }^{13}$ Berdasarkan teori Pendidikan Nasionaltersebut memiliki persamaan dengan tujuan pembelajaran yang ada di MAN 1 Lamongan terkhusus pada pembelajaran Akidah Akhlak.

Berkaitan dengan penghargaan yang diterima oleh MAN 1 Lamongan yang menjadi sekolah berprogram Adiwiyata sehingga pada pembelajaran Akidah Akhlak mampu memberikan pengajaran mengenai norma serta etika yang menjadi dasar manusia menuju terciptanya kesejahteraan dengan lingkungan sekitar.

Pada program Adiwiyata memodivikasi kurikulum menggunakan system integrasi lingkungan hidup di masing masing pelajaran sebagai ganti system pendidikan lingkungan hidup yang bersifat monolitik. Oleh karena itu siswa siswi mampu memiliki pengetahuan dan kesadaran akan peduli lingkungan dengan cara menanamkan akhlak yang baik, pengajaran etika, aturan serta norma norma yang ada dalam suatu pembelajaran Akidah Akhlak, dengan ini pembelajaran Akidah Akhlak diharapkan mampu membimbing dan memberi wawasan akan penanaman adab, etika, norma serta akhlak mterpuji baik kepada sesama manusia dan lingkungan yang ada disekitar.

Berkaitan dengan implementasi pembelajaran Akidah Akhlak dalam meningkatkan karakter peduli lingkungan di sekolah Adiwiyata MAN 1 Lamongan di katakan sudah berhasil apabila sudah memenuhi tujuan pembelajaran, tujuan pembelajaran diantaranya adalah :

\section{a. Tujuan Institusional}

institusional merupakan tujuan yang akan dicapai Lembaga yang menyelenggarakan pendidikan, seperti Visi dan Misi sekolah. Untuk tercapainya Visi dan Misi sekolah maka guru Akidah Akhlak harus mampu membimbing dan mengawasi siswa siswi agar memiliki Akhlak atau adab yang baik melalui proses pembelajaran mengajar, pengalaman, pembiasaan, penghayatan dan kayakinan, terutama pada penumbuhan adab dan kesadaran Peduli lingkungan di sekolah yang berprogram Adiwiyata MAN 1 Lamongan. Dengan adanya pembelajaran Akidah Akhlak akan dapat mempermudah penerapan budaya lingkungan, dimana budaya lingkungan tersebut terbentuk dari pengajaran Akhlak dan Adab yang diajarkan oleh guru Akidah Akhlak.

\footnotetext{
${ }^{13}$ Wina Sanjaya, Perencanaan dan Desain Sistem Pembelajaran (Jakarta : KENCANA Prenadamedia Group : 2008), 124
} 
b. Tujuan instructional

Tujuan instructional yaitu tujuan pembelajaran lebih menekankan pada siswa meliputi aspek kemampuan dan keterampilan tertentu, untuk tujuan umum pada pembelajaran Akidah Akhlak di MAN 1 Lamongan ini condong kepada tujuan Oprasional pada siswa yang telah melakukan kegiatan pembelajaran. Tujuan pembelajaran Akidah Akhlak dalam meningkatkan karakter peduli lingkungan :

1) Siswa mampu memiliki Adab atau Akhlak yang baik/ terpuji. Akhlak yang baik tersebut termasuk Akhlak baik terhadap diri sendiri, orang lain maupun dengan lingkungan yang ada di sekitar dengan tidak merusak lingkungan.

2) Pembelajaran Akidah mampu mengarahkan dan membimbing siswa untuk membentuk Akhlak terhadap Allah SWT dan memiliki karakter pribadi yang baik terhadap guru, orang tua, teman maupun lingkungan melalui proses belajar mengajar yang dilakukan.

3) Siswa mampu melakukan dan melaksanakan visi dan misi yang ada di sekolahan yang berkaitan dengan sikap peduli lingkungan, dengan visi "Terwujudnya Generasi Islam yang Unggul dalam Prestasi, Terampil Berbudaya Lingkungan Hidup"

\section{Proses Pembelajaran Akidah Akhlak dalam Meningkatkan Karakter Peduli Lingkungan}

Berdasarkan Peraturan Menteri Pendidikan Nasional (Permendiknas) Nomor 41 tahun 2007 tentang standar proses untuk satuan pendidikan dasar dan menengah, bahwa standar proses berisi kriteria minimal proses pembelajaran pada satuan pendidikan dasar dan menengah diseluruh wilayah hukum Negara Kesatuan Republik Indonesia. Standar proses meliputi perencanaan proses pembelajaran, pelaksanaan proses pembelajaran, penilaian hasil pembelajaran, dan pengawasan hasil pembelajaran untuk terlaksananya proses pembelajaran yang efektif dan efisien. ${ }^{14}$

Sesuai dengan peraturan tersebut pada proses pembelajaran yang dilakukan oleh guru Akidah Akhlak dalam meningkatkan karakter peduli lingkungan melalui beberapa tahapan :

\section{Perencanaan}

Setiap pembelajaran yang dilakukan tidak lepas dari suatu perencaan yang harus dimiliki oleh setiap pendidik atau guru, maka dari itu perencanaan yang dilakukan harus dimulai dari penetapan tujuan yang akan di capai Oleh karena itu Guru Akidah Akhlak di MAN 1 Lamongan dalam meningkatkan karakter peduli lingkungan kepada siswa siswinya melakukan beberapa tahap penyusunan, penyusunan yang dilakukan oleh guru tersebut meliputi hal hal berikut :

\footnotetext{
${ }^{14}$ Peraturan Menteri Pendidikan Nasional No.41 tahun 2007 pasal 1 tentang standar proses penmbelajaran untuk satuan menengah
} 
a. Materi Pelajaran

Pada penyampaian materi atau sub bab yang diajarkan guru Akidah Akhlak kepada siswa siswi nya semuanya dikaitkan dengan penanaman karakter peduli lingkungan, dikarenakan sekolah MAN 1 Lamongan merupakan sekolah yang berprogram Adiwiyata maka diharuskan semua mata pelajaran harus di integrasikan atau di selipkan mengenai tentang penumbuhan kesadaran akan peduli lingkungan.

b. Metode

1) Diskusi

Penggunaan metode diskusi menjadi metode pembuka pada proses pembelajaran yang dilakukan oleh guru Akidah Aklak, karena diskusi yang dilakukan dengan mengembangkan dan menggabungkan pemikiran siswa siswi MAN 1 Lamongan untuk lebih mudah dalam mencapai suatu tujuan pembelajaran. Dengan ini guru akidah akhlak mampu mengetahui karakter setiap peserta didik, dari yang aktif maupun yang pasif.

2) Ceramah

Guru Akidah Akhlak sering memberikan masukan atau informasi dengan cara menjelaskan secara langsung bertatap muka bahwasanya selain Akhlak yang baik terhadap Allah, manusia setiap siswa harus memiliki adab atau Akhlak yang baik terhadap lingkungan dengan selalu menjaga lingkungan yang ada disekitar, baik kelas maupun sekolah.

3) Tanya Jawab

Tanya jawab yang dilakukan oleh guru Akidah Akhlak MAN 1 Lamongan biasanya berada di bagian akhir pembelajaran saat terlaksananya metode pembelajaran diskusi dan ceramah. Untuk mengetahu hasil dari pembelajaran yang dilakukan maka guru akidah Akhlak menggunakan Tanya jawab di akhir pelajaran,

c. Media

Media merupakan pemanfaatan komponen alat dalam system pembelajaran. Pada proses pembelajaran Akidah Akhlak media yang dipakai berfariasi sesuai dengan kebutuhan pada pembelajaran yang dilakukan oleh siswa-siswi. Seperti halnya berkaitan dengn metode diskusi yang dilakukan oleh guru Akidah Akhlak, pada metode diskusi tersebut media yang dipakai adalah proyektor,laptop,papan tulis, buku dan lain lain yang dapat dijadikan sebagau media belajar. Selain itu media yang digunakan berkaitan dengan penanaman peduli lingkungan pada siswa yaitu setiap guru harus bisa memanfaatkan media kelas,

d. Strategi

Strategi yang digunakan guru Akidah Akhlak dalam menumbuhkan kesadaran akan peduli lingkungan yaitu dengan selalu melestarikan lingkungan yang ada seperti membuang sampah pada tempatnya, menjaga selalu kebersihan kelas. 
e. Evaluasi

Pada penilaian atau pengevauasian yang dilakukan oleh guru Akidah Akhlak di MAN 1 Lamongan biasanya menggunakan 2 penilaian, yang pertama menggunaka ulangan harian yang berbentuk esay yang kedua kebiasaan atau keaktifan siswa siswi atau adab keseharian pada proses pembelajaran berlangsung.

2. Pelaksanaan

Pelaksanaan pembelajaran guru mampu mengimplementasikan teori yang berkaitan dengan teori belajar terhadap realita pembelajaran yang sebenarnya. Seperti yang dikemukakan oleh Roy R. Lefrancois (yang dikutip oleh Dimyati Mahmud) menyatakan bahwa : pelaksanaan pembelajaran terdiri dari kegiatan pembuka sampai penutup yang terbagi menjadi pendahuluan, inti dan penutup,dengan disertai strategi yang telah dirancang untuk mencapai tujuan pembelajaran.

Untuk itu pada pelaksanaan pembelajaran guru Akidah melalui tiga tahap pembelajaran :

a. Pendahuluan

Pertama memeriksa kebersihan kelas sebagai media pembelajaran yang utama, menyeru siswa siswi untuk memeriksa lingkungan belajar dengan memungut sampah yang ada di sekitar tempat belajar, setelah itu baru salam, Kedua memeriksa kehadiran siswa dan berdoa bersama, ketiga menjelaskan tujuan pembelajaran mengenai materi yang akan disampaikan.

b. Inti

Kegiatan pembelajaran di bagian inti lebih kepada penyampaian materi sesuai dengan Standart Kompetensi (SK) dan Kompetensi dasar (KD).

c. Penutup

Kegiatan penutup pembelajaran Akidah Akhlak lebi memfokuskan dengan mengulas kembali materi yang telah di sampaikan,dan melakukan sesi Tanya jawab,

\section{Sumber Daya dalam Meningkatkan Karakter Peduli Lingkungan di Sekolah Adiwiyata MAN 1 Lamongan}

Sumber belajar merupakan bahan untuk menambah ilmu pengetahuan yang mengandung hal hal baru, menurut Association For Educational Comunications dan Technology sumber belajar adalah segala sesuatu yang dapat dimanfaatkan oleh guru untuk ke efektivan tujuan pembelajaran,terdapat lima macam yaitu sumber daya Manusia, bahan ajar,pendekatan,aktivitas dan lingkungan,yang dapat dimanfaatkan dalam proses pembelajaran ${ }^{15}$ :

${ }^{15}$ https://www.google.co.id/amp/s/.www.silabus.web.id/sumber-belajar/.amp/. 
1. Manusia

Di MAN 1 Lamongan pengembangan sumber daya manusia pada dasarnya berasal dari seorang pendidik atau guru melalui proses pelatihan, seminar atau work shop yang diikuti oleh ketua Adiwiyata yang sudah di bentuk. Setelah mengikuti seminar, maka perwakilan tersebut menjelaskan dan menyampaikan hasil seminar tersebut kepada warga MAN 1 Lamongan pada saat upacara berlangsung.

2. Bahan Pengajaran

Bahan ajar yang dipakai pada pelaksanaan pembelajaran Akidah Akhlak lebih menfokuskan pada buku yang sudah di sediakan oleh pihak sekolah seperti LKS,kitab dan Internet untuk menambah wawasan siswa sisiwi pada pembelajaran.

3. Alat atau perlengkapan

Perangkat pembelajaran yang dipakai guru Akidah Akhlak untuk menyampaikan materi ataun bahan ajar lebih sering menggunakan proyektor, laptop atau komputer, Hp, tape recorder.

4. Aktivitas

Dalam pengimplementasian pembelajaran Akidah Akhlak dalam membangun kesadaran peduli lingkungan siswa, dilakukan melalui kegiatan yang dilakukan oleh pendidik melalui proses belajar, dengan menanamkan adab yang baik, berperilaku yang baik dan memiliki etika, sehingga pada pembelajaran Akidah Akhlak memiliki peran dalam pencegahan kerusakan pada lingkungan.

5. Lingkungan

Lingkungan merupakan faktor yang mempengaruhi belajar siswa. Berkaitan dengan sumber daya lingkungan yang ada di MAN 1 Lamongan baik dalam kelas maupun di luar kelas dimana kedua duanya menunjukkan akan sangat pentingnya peduli terhadap lingkungan. Kalau didalam kelas lebih kepada keadaan kelas dan siswa siswi dalam menjaga kebersihan lingkungan yang ada didalam kelas, sedangkan kalau diluar kelas lebih kepada pelataran kelas yang diluaar kelas terdapat berbagai macam bunga dan tong sampan organic dan non organic sehingga Nampak asri dan bersih dan menjadi cerminan berbudaya lingkungan hidup.

\section{Kesimpulan}

Berdasarkan hasil penelitian tentang Implementasi Pembelajaran Akidah Akhlak dalam Meningkatkan Karakter Peduli Lingkungan Di Sekolah Adiwiyata di MAN 1 Lamongan dapat di tarik kesimpulan antara lain bahwa tujuan Pembelajaran Akidah Akhlak dalam Meningkatkan Karakter Peduli Lingkungan di sekolah Adiwiyata MAN 1 Lamongan meliputi pertama Tujuan institutional tujuan institutional ini lebih kepada tercapainya visi dan misi yang ada di MAN 1 Lamongan Kedua Tujuan instructional, Tujuan Instructional ini lebih kepada keterampilan siswa agar memiliki karakter peduli terhadap lingkungan hidup. Selain itu, proses Pembelajaran Akidah Akhlak dalam Meningkatkan Karakter Peduli Lingkungan di sekolah Adiwiyata MAN 1 Lamongan mulai dari perencanaan materi pembelajaran, metode, media,strategi serta pengevaluasian. Serta Pelaksanaan yang terdiri dari Pendahuluan, Isi dan Penutup. Sedangkan sumberdaya pembelajaran sangat dikembangkan dengan sebaik baiknya, 
seperti sumberdaya manusia, sumber daya manusia tidak lain adalah guru yang ada di MAN 1 Lamongan, sumber daya bahan ajar di MAN 1 Lamongan menggunakan LKS dan kitab serta internet sebagai pelengkap, sumberdaya alat atau perlengkapan, pada sumberdaya ini perlengkapan yang digunakan seperti pemanfaatan proyektor,tipe, recorder, laptob, sumberdaya akivitas, pada sumberdaya aktivitas itu sesuai dengan proses pembelajaran dan sumber daya lingkungan, sumberdaya lingkungan dengan memanfaatkan kelas sebagai media utama pada pembelajaran.

\section{Daftar Rujukan}

Arikunto, Suharsimi. Prosedur Penelitian Suatu Pendekatan Praktik. Jakarta: Rineka Cipta, 2014.

Daryanto, dan Darmiatun, Suryanti. Implementasi Pendidikan Karakter di Sekolah. Yogyakarta: Gava Media, 2013.

Gunawan, Heri. Pendidikan Karakter Konsep dan Implementasi. Bandung: Alfabeta, 2014.

Hamid, Hamdani. Pendidikan Karakter Islam. Bandung : Pustaka Setia, 2013.

Natta, Abibuddin. Akhlak Tasawuf. Jakarta : PT Rajagrafindo Persada,1996.

Ramayulis. Metodologi Pendidikan Islam. Jakarta : Radar Jaya Offset, 2014.

Sugiyono. Metode Penelitian Kuantitatif, Kualitatif dan R\&D. Bandung: Alfabeta, 2015.

Anggreiny, Irma. "Pengertian Implementasi", dalam http://elkawaqi.blogspot. com/2012/12/pengertian-implementasi-menurut-para.html, diakses pada 1 Januari 2019.

Kamus Besar Bahasa Indonesia (KBBI) Online. Dalam https://kbbi.kata.web.id/ tatatertib/, diakses pada 1 Januari 2019.

Lembaga Penelitian Mahasiswa Penalaran Universitas Negeri Makassar, "Metode Penelitian Kualitatif Dengan Jenis Pendekatan Studi Kasus", dalam http://penalaran-unm.org/metode-penelitian-kualitatif-dengan-jenispendekatan-studi-kasus/, diakses pada 26 Ferbuari 2019.

Tim Adiwiyata Tingkat Nasional, Panduan Adiwiyata : Sekolah Peduli Lingkungan Dan Budaya Lingkungan, (Jakarta : Kementrian Lingkungan Hidup Dan Kementrian Pendidikan Dan Kebudayaan, 2011)

Fata, Khoirul, Ahmad, "Teologi Lingkungan Hidup dalam Perspektif Islam",Jurnal Ulul Albab, Vol.15, No.02 (2014)

Majid,Abdul dan Andayani,Dian. Pendidikan Agama Islam Berbasis Kompetensi (Konsep Implementasi Kurikulum 2004).Bandung Remaja Rosda Karya, 2005).

Anwar,Rosihon. Akidah Akhlak. Bandung : Pustaka Setia, 2014

Sanjaya,Wina. Sistem Pembelajaran. Jakarta : Kencana Prenadamedia Group, 2008.

Hamid, Hamdani. Pendidikan Karakter Perspektif Islam.Bandung : Pustaka Setia,2013 